International Scientific Organization http://iscientific.org/

Chemistry International

www.bosaljournals.com/chemint/

\title{
Kaolin and bentonite catalysts efficiencies for the debutylation of 2-tert- butylphenol
}

\section{Rokhsana Mohammed Ismaili, Wael Qasem Almaqtri² and Mohammed Hassan ${ }^{3,4, *}$}

${ }^{1}$ Chemistry Department, Faculty of Science, Aden University, Aden, Yemen

${ }^{2}$ Faculty of Medical laboratories (Department of Chemistry), Jibla University for Medical and Health Sciences, Ibb, Yemen

${ }^{3}$ Chemistry Department, Faculty of Science, Ibb University, Ibb, Yemen

${ }^{4}$ Department of Basic Sciences and Mathematics, Faculty of Science, Philadelphia University, Jordan

*Corresponding author's E. mail: m-hassan@ibbuniv.edu.ye

\section{Article type:}

Research article

\section{Article history:}

Received February 2020

Accepted July 2020

January 2021 Issue

Keywords:

Reduction

Calcination

Clay

De-tert-butylation

Catalytic activity
Yemeni clays (bentonite and kaolin) were used as catalysts and catalysts supported metals ions $\mathrm{Ce}, \mathrm{Pt}, \mathrm{Pt}-\mathrm{Ce}, \mathrm{Pd}, \mathrm{Pd}-\mathrm{Ce}$, for the debutylation reaction of 2tert-butylphenol. The two clays were characterized using atomic absorption spectroscopy, particle size analyzer and $\mathrm{N}_{2}$-BET adsorption method. The activity of debutylation reaction was found to depend on the type of the catalyst. Kaolin based catalysts were more active than those bentonite based. The Selectivity of the catalysts was found to depend on the type of treatment that each catalyst was subjected to. The catalysts that were treated by calcination were more selective towards phenol formation (debutylation reaction of 2-tertbutylphenol), while those treated by reduction were more selective toward the formation of 4-tertbutylphenol (isomerization reaction of 2-tertbutylphenol).

(C) 2021 International Scientific Organization: All rights reserved.

Capsule Summary: Yemeni clays (bentonite and kaolin) were tested as catalysts and catalyst supports for debutylation of 2tertbutylphenol. Kaolin based catalyst showed better activity, while bentonite exhibited better selectivity toward phenol production.

Cite This Article As: R. M. Ismail, W. Q. Almaqtri and M. Hassan. Kaolin and bentonite catalysts efficiencies for the debutylation of 2-tert-butylphenol. Chemistry International 7(1) (2021) 21-29.

https://doi.org/10.5281/zenodo.4018036

\section{INTRODUCTION}

Clays and clay minerals are growing in their applications in various fields. There are well over one hundred documented industrial applications of clay materials (Savic and Stojiljkovic, 2014). They are utilized in the process industries, agricultural applications, engineering and construction applications, environmental remediation, geology, and many other miscellaneous applications (Cremades et al., 2014; Loganathan et al., 2016; Kim et al., 2016). Clay uses and properties are largely dependent on their mineral structure and composition. In addition to the structure and composition, other properties are also important in deciding clay to a certain application, namely; non-mineral constituents of the clay and its ability to exchange ions and soluble salts (Murray, 2007).

Kaolinite group minerals consist of uncharged dioctahedral layer units with a $1: 1$ structure of $\approx 7 \mathrm{~A}^{\circ}$ in thickness and of the formula $\mathrm{AI}_{4} \mathrm{Si}_{4} \mathrm{O}_{10}(\mathrm{OH})_{8}$. The kaolinite layer can be regarded as the result of a fusion of the $\left(\mathrm{Si}_{2} \mathrm{O}_{5}\right)_{\mathrm{n}}{ }^{-2}$ sheet and the $\mathrm{Al}(\mathrm{OH})_{3}$ (gibbsite) sheet (Varga, 2007). 
Bentonite is the name of a rock containing more than $90 \%$ montmorillonite. Montmorillonite is a 2:1 layered clay consisting of two layers of $\mathrm{SiO}_{4}$ tetrahedra sandwiching a layer of Aluminum atoms in octahedral coordination (Occelli et al., 1993). Montmorillonite consists of a negatively charged layers with a typical composition of $(\mathrm{Al}, \mathrm{Mg})(\mathrm{Si}-\mathrm{Al})_{4} \mathrm{O}_{10}(\mathrm{OH})_{2}$ and interlayer cations compensating the positive charge deficiency of the silicate layers (Uddin, 2018).

Transition metals such as Mn and Fe oxides, as well as $\mathrm{K}$ and Na-oxides are also contained in theses clays and are expected to affect the catalytic activity of these clays by acting as promoters and/or being themselves catalysts for some reactions. For instance, the presence of highly charged metal ions in these clays would enhance the Lewis /Brönsted sites ratio, so that they may affect the catalyst activity and/or selectivity (Novikova et al., 2014). Natural clays have acidic sites on their surfaces, which made them to be as catalysts. Acid-activated kaolin clays have been used to prepare cracking catalysts (Emam, 2013). Calcination of kaolin followed by acid activation gives a catalyst of the same activity as activated montmorillonite at about one-half of the fresh surface area. The acid-activated kaolin has fewer acid sites than acid-treated montmorillonite, but all sites are very strongly acidic (Lussier, 1991).

Yemen's geology has characterized by diversity rocky includes all types of sedimentary, igneous, and metamorphic rocks are spread in different places, its ages ranging from pre-Cambrian to Cenozoic age (Albaroot et al., 2016). Geology of Yemen is a part of the Arab and African region which represents the great diversity of rocks with geological conditions that are compatible with the ideal rock models recorded regionally and globally. Yemeni clays contain a high percentage of the active ingredients which may make it of potential industrial applications (AL-Shameri and Lei, 2009). Yemen has not recognized the manufacturing of the clays and this study is the first study in Yemen which highlights the importance of clays and their use as catalysts (Vicente et al., 2010).

Here, we have chosen two types of clays (kaolin and bentonite) collected from Yemen to test their efficiency as catalysts and/or catalyst supports for de-tert-butylation of 2tert-butyl-phenol. This reaction is a model for the dealkylation of aromatic compounds, where isomerization (trans-alkylation) is expected as a competing reaction. Therefore, there would be a wide spectrum of investigations concerning this reaction, i.e., debutylation, tert-butyl group migration, and trans-alkylation. All of these possibilities are expected to be affected by the clay composition, acid treatment, as well as the metal loaded on the surface of the clay.

\section{MATERIAL AND METHODS}

\section{Preparation of clays samples}

The chemicals that were used in this work and their suppliers are given in Table 1. All chemicals were used as received without further purification. Two types of clays were used throughout the work; kaolin (a sample was obtained from Geological and mineral agency, Yemen) and was without further purification and bentonite (a sample brought from Hadramout region, Yemen) and subjected to purification as follows: Mozely hydrocylone (2 inches) was used for separation of the undesired non-clay materials. The feed (bentonite) plus the dispersing agent (sodium hexametaphosphate) were mixed with water and passed through $0.50 \mathrm{~mm}$ sieve. They introduced to the hydrocyclone through the inlet pipe under pressure of 25 bar. As a result of the high centrifugal forces, the coarse particles move downward and discharged through the vortex finder pipe (overflow $8 \mathrm{~mm}$ ). The overflow was collected and left to dry in air. Thereafter, the two types of clays were crushed, milled using a steel ball mill, and then they were sieved using $\leq 63$ $\mu \mathrm{m}$ sieve (mesh No. 230). The clays particle with size $\leq 63 \mu \mathrm{m}$ were taken and used later.

\section{Elemental analysis}

About $0.20 \mathrm{~g}$ of each clay (without acid treatment) was weighed and put into $100 \mathrm{ml}$ plastic bottle: ( $5 \mathrm{ml}$ of $40 \% \mathrm{HF}$, $2.5 \mathrm{ml}$ of $25 \% \mathrm{HCl}$ and $2.5 \mathrm{ml}$ of $25 \% \mathrm{HNO}_{3}$ ) were added. The mixture was left for $2 \mathrm{hrs}$ in a water bath at $70 \mathrm{C}^{\circ}$ with shaking, $50 \mathrm{ml}$ of Boric acid ( $39 \mathrm{~g} / \mathrm{L}$ ) was added and $40 \mathrm{ml}$ of distilled water were added; then $10 \mathrm{ml}$ of the solution were taken and67 diluted to $100 \mathrm{ml}$ so that to get a $(10 \% \mathrm{~V} / \mathrm{V})$ solution. The analysis of these elemental was made by using (Pye Unicam SP9) Atomic Absorption Spectrophotometer (AAS).

\section{Particle size analysis and surface area}

About $1 \mathrm{~g}$ of the clay was placed in relatively large test tube which was half-filled with distilled water. A dispersing agent (Sodium hexameta phosphate) was added; then the whole mixture was shaken and left for two days to insure complete dispersion. The grain size analysis was carried out using the (Fritsch Particle-Size Analyzer 20). Surface area measurements were carried out using BET method using $\mathrm{N}_{2}$ adsorption.

\section{Acid treatment}

All samples that were used as catalysts in this work were subjected to acid treatment. A hydrochloric acid solution of $\mathrm{pH}=4$ was prepared and used in the acid treatment of the clays. About $100 \mathrm{~g}$ of each clay was taken and put in a large flask; then, the acid solution was added to it and the mixture was shaken. The mixture was left overnight and the clay was filtered under vacuum. The clay was then washed with distilled water. The clays were acidified and then dried overnight in an oven at $70 \mathrm{C}^{\circ}$.

\section{Impregnation}


Table 1: Chemicals and their suppliers

\begin{tabular}{lc}
\hline Chemical & Supplier \\
\hline Sodium hexameta phosphate & J.C.L.E \\
2-tert- butylphenol & Janssen Chimica \\
Methanol, HPLC & Baker Analyzed \\
Phenyl acetylene & Ferak Laboral \\
Platinum (IV) chloride & Janssen Chimica \\
Palladium (II) bromide & Ferak Laboral \\
Cerium (III) nitrate, Ce(NO3)3.6 $\mathrm{H}_{2} \mathrm{O}$ & Fluka - Garantie \\
Hydrochloric acid $36.5 \%-38 \%$ & Baker Analyzed \\
Nitric Acid 69-72\% & BDH Chemical Ltd \\
Aluminum oxide 90 activity & Merck \\
Activated carbon & Fluka Chemica \\
He gas & Arab Supply Co \\
Compressed air & Arab Supply Co. \\
H2 gas & Arab Supply Co. \\
\hline
\end{tabular}

Table 2: Catalysts used in the tert-debutylation reaction

\begin{tabular}{lc}
\hline Prepared catalyst & Type of treatment \\
\hline Bentonite & Calcined or reduced \\
Kaolin & Calcined or reduced \\
$5 \%$ Pt on bentonite & Calcined or reduced \\
$5 \%$ Pt on kaolin & Calcined or reduced \\
$5 \%$ Pd on bentonite & Calcined or reduced \\
$5 \%$ Pd on kaolin & Calcined or reduced \\
$5 \%(P t-C e)$ on bentonite & Calcined or reduced \\
$5 \%(P t-C e)$ on kaolin & Calcined or reduced \\
$5 \%(P d-C e)$ on bentonite & Calcined or reduced \\
$5 \%(P d-C e)$ on kaolin & Calcined or reduced \\
Ce-cation exchange with bentonite & No treatment \\
Ce-cation exchange with kaolin & No treatment \\
Activated Aluminum oxide & No treatment \\
Activated charcoal & No treatment \\
\hline
\end{tabular}

Appropriate concentrations of salt solution of $\mathrm{PtCl}_{4}, \mathrm{PdBr}_{2}$, $\mathrm{Ce}\left(\mathrm{NO}_{3}\right)_{3} .6 \mathrm{H}_{2} \mathrm{O}$ were prepared and used to impregnate $9.5 \mathrm{~g}$ samples of (bentonite and kaolin). The mixture was shaken well and was left to dry overnight in the oven at $70{ }^{\circ} \mathrm{C}$.

\section{Cation exchange}

An appropriate concentration of $\mathrm{Ce}\left(\mathrm{NO}_{3}\right)_{3} \cdot 6 \mathrm{H}_{2} \mathrm{O}$ solution was prepared and used for the cation exchange of bentonite and kaolin; they were immersed in the solution and left for overnight to insure complete exchange. Then the clay was filtered, washed with distilled water and left to dry in the oven at $70 \mathrm{C}^{\circ}$.

\section{Calcination and reduction}

A glass fixed-bed flow reactor was used for calcination and reduction of the catalysts. Calcination was performed by placing the catalyst in the reactor, which was heated using a tubular Pyrex electric oven. The temperature measurements were performed by a thermocouple thermometer inserted in the thermowell located at the bottom of the reactor. The temperature was controlled by adjusting the input voltage of the electric oven using a variable AC transformer.

Flow-rate of gases was controlled by (Matheson) four-channel manual flow meter controller. The air flow was at the rate of $45 \mathrm{ml} / \mathrm{min}$ at $500{ }^{\circ} \mathrm{C}$ for $1.5 \mathrm{~h}$. Reduction was achieved by introducing helium followed by introduction of hydrogen at a flow rate of $100 \mathrm{ml} / \mathrm{min}$ through the catalystbed for $2 \mathrm{~h}$ at the same temperature used for calcination. The catalyst was then cooled to room temperature in a Helium atmosphere. 


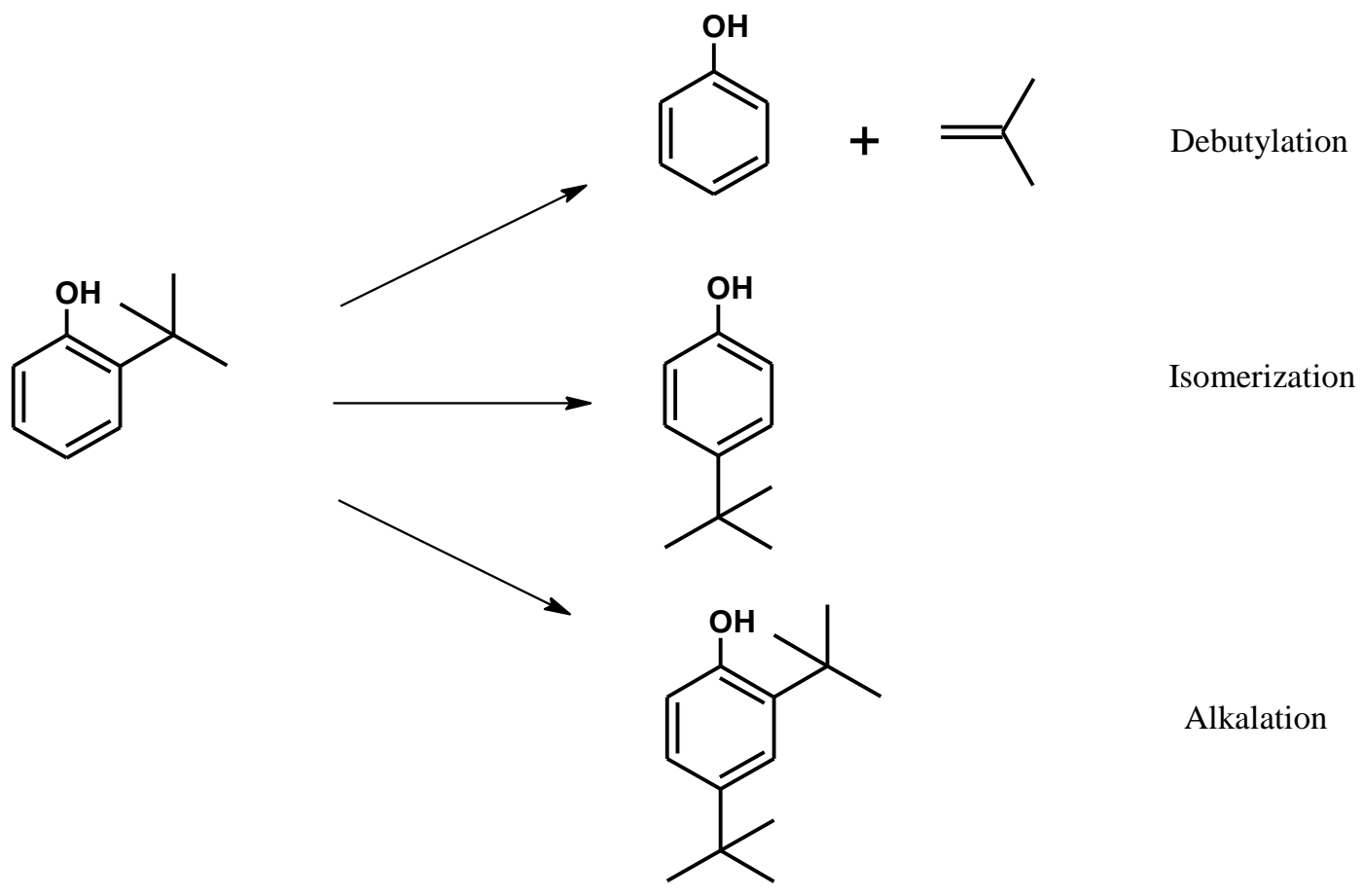

Scheme 1: Various catalyzed conversion paths of 2-tertbutylphenol
0. Flow Meter.
1. Gas Value.
2. Glass Tube.
3. Flow Bed Catalytic Reactor.
4. Powalered Sample.
5. Glass Dise.
6. Electrical Resistunce.
7. Electronic Thermometer
8. Trap.
9. Indicator.

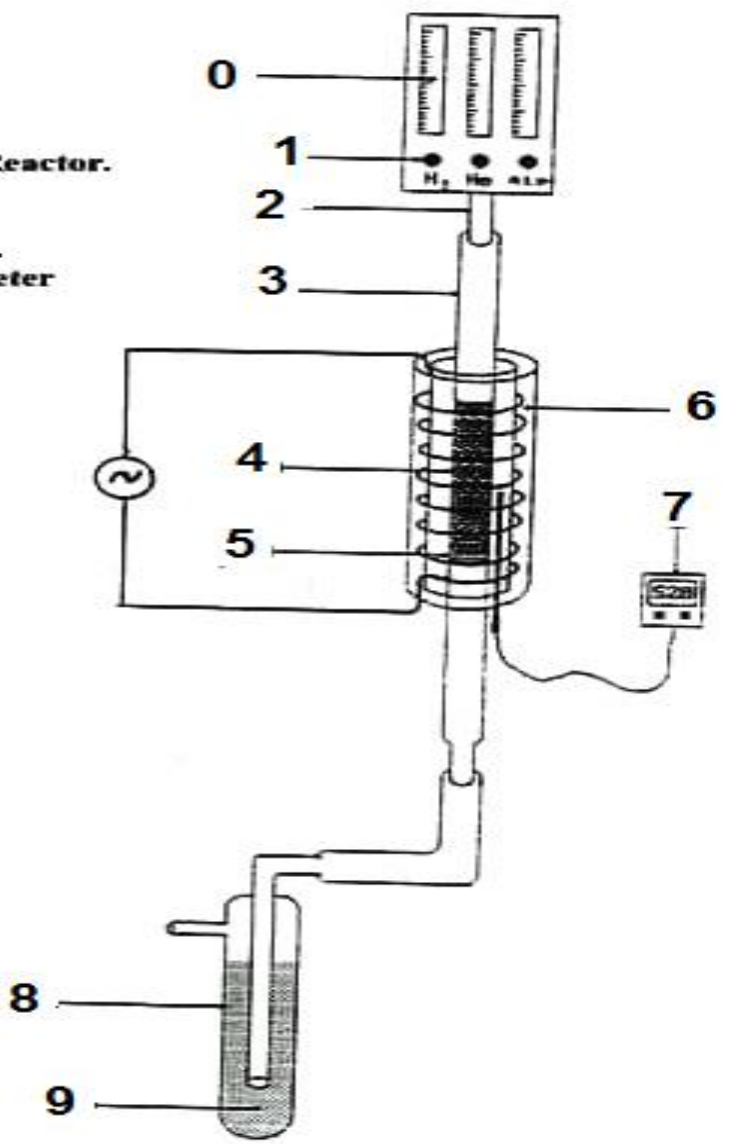

Fig. 1: Graphical representation of the reactor used to study the reaction of de-tertbutylation of 2-tertbutylphenol catalyzed by kaolin and bentonite clays and bentonite clays 


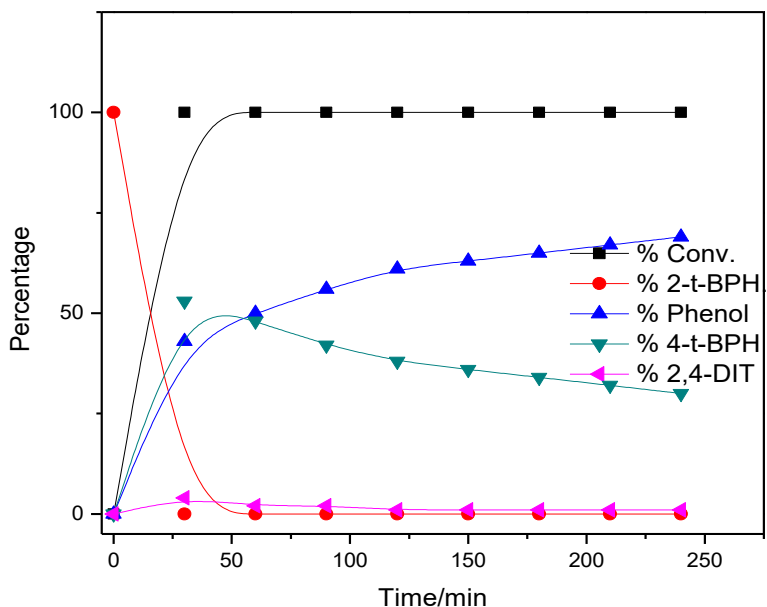

Fig. 2: De-tertbutylation of 2-tert-butylphenol over kaolin at $210{ }^{\circ} \mathrm{C}$ after acid pretreatment at $\mathrm{pH}=4$ and calcination then reduction

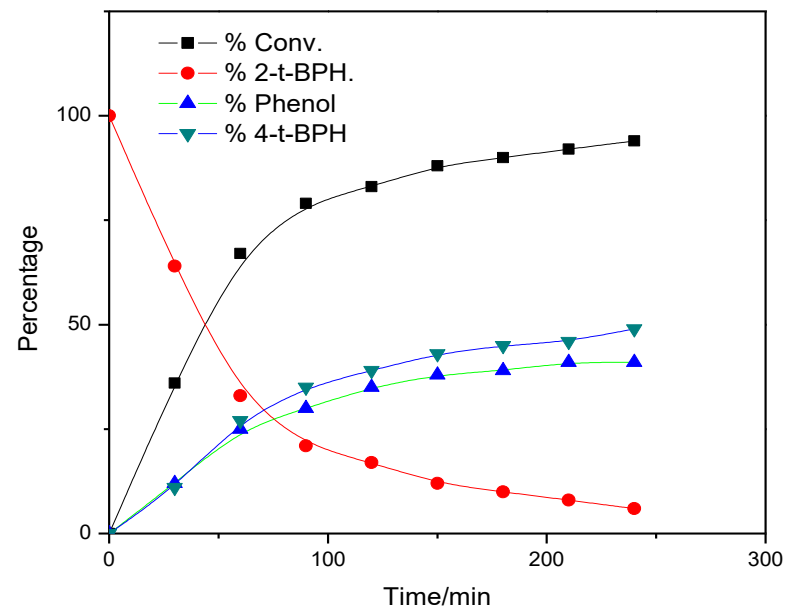

Fig. 3: Debutylation of 2-tert-butylphenol by calcined bentonite

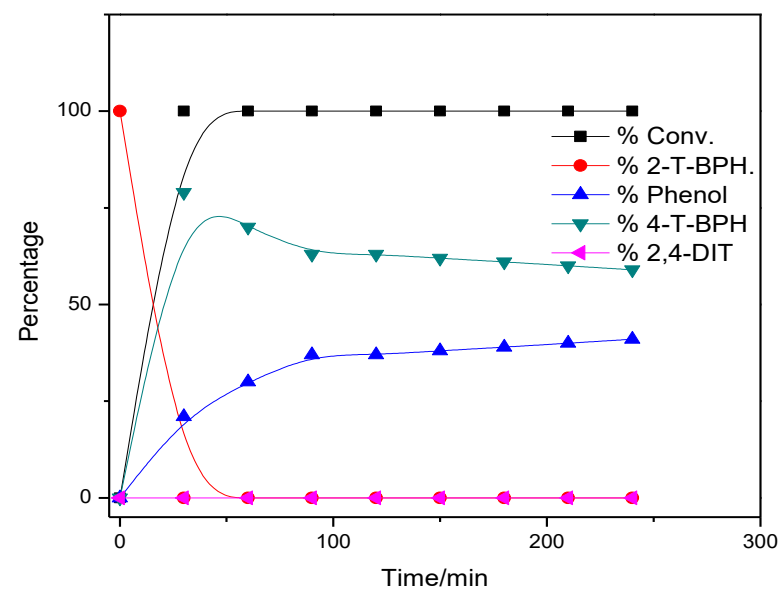

Fig. 4: Debutylation of 2-tert-butylphenol by Ceexchanged bentonite at $210{ }^{\circ} \mathrm{C}$

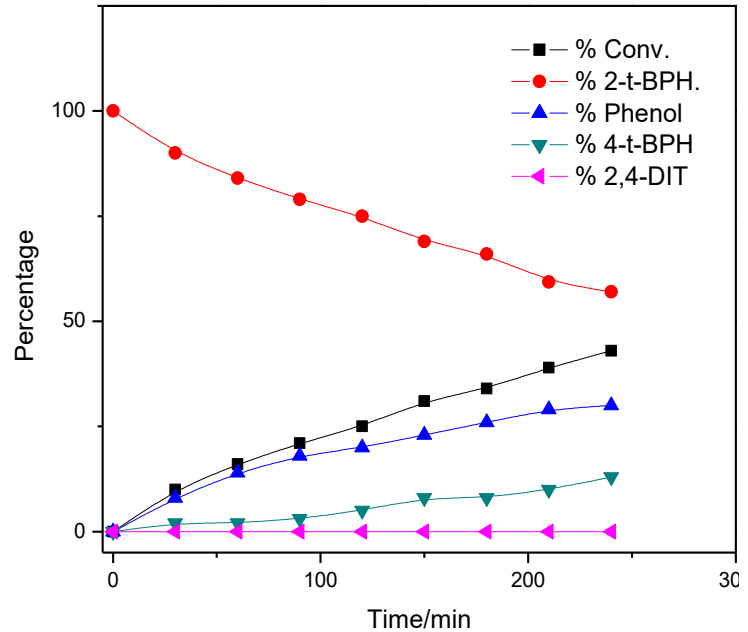

Fig. 5: Debutylation of 2-tert-butylphenol by reduced $5 \%\left(\mathrm{Pt}-\mathrm{Ce}\right.$ ) kaolin at $210^{\circ} \mathrm{C}$

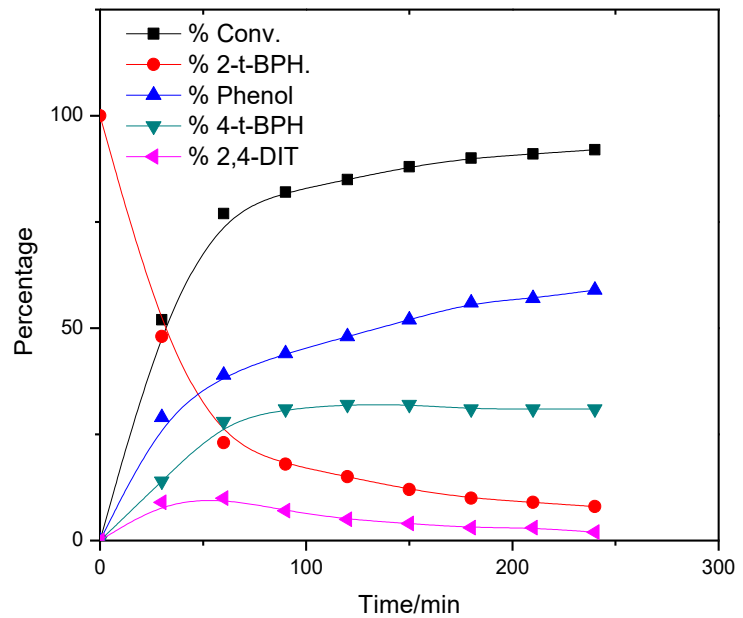

Fig. 6: Debutylation of 2-tert-butylphenol by reduced $5 \% \mathrm{Pd}-\mathrm{kaolin}$ at $210{ }^{\circ} \mathrm{C}$

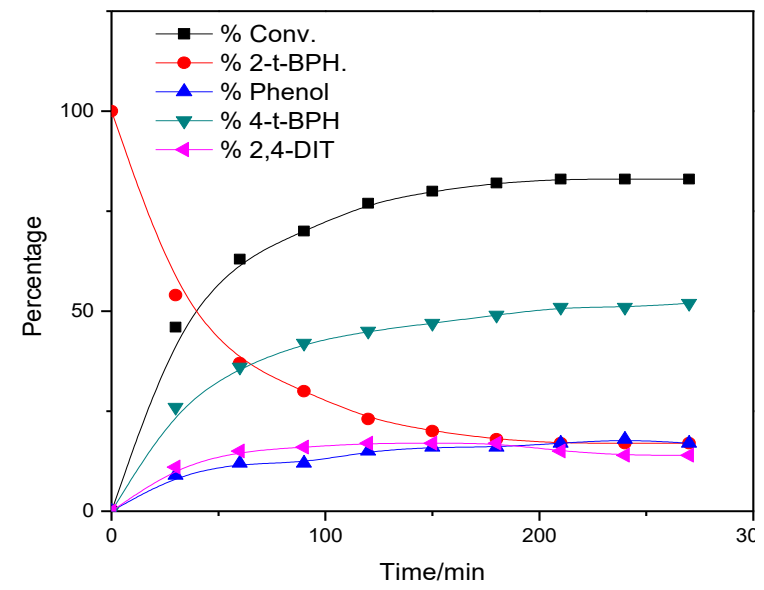

Fig. 7: De-butylation of 2-tert-butylphenol by reduced $5 \% \mathrm{Pt}$-Kaolin $210{ }^{\circ} \mathrm{C}$ 


\section{Use of catalysts for debutylation reaction}

Various catalysts that were prepared from the two clays were tested for their efficiency in enhancing reactivity and selectivity of de-2-tert-butylation of 2-tert butylphenol (Scheme 1). Figure 1 shows the graphical display of the reactor used to carry out the catalyzed reaction. It consists of a $30 \mathrm{~cm}$ long $X 2.5 \mathrm{~cm}$ O.D. glass tubing with a fritted glass disc positioned at the top of its lower third; the upper end of the reactor is connected by copper tubing to a four-channel flow meter controller. The lower end of the reactor is connected by Tygon tubing to a trap filled with sodium hydroxide solution and phenolphthalein indicator (to insure the flow of gases and to trap any liberated acid). The trap is ducted to the outside by Tygon tubing. 2-tert butylphenol (5 $\mathrm{ml}$ ) with $0.50 \mathrm{~g}$ catalyst was transferred into a $50 \mathrm{ml}$ threenicke round bottom flask. Then the flask was heated under reflux in an oil bath to insure a constant reflux temperature. After 30 minutes intervals for a period of four hours, a sample was taken into a small vial containing methanol as a diluting solvent. Then the sample was analyzed using a gas chromatograph (Pye-Unicam ) with an FID detector and 1.5 $\mathrm{m}, 6 \mathrm{~mm}$ stainless steel column packed with silicon E30 (E301) 10\% supported on silanized acid washed Diatomaceous earth " C " mesh No. 2. Helium, as the carrier gas was introduced at a flow rate of $45 \mathrm{ml} / \mathrm{min}$. The catalysts that were investigated in enhancing reactivity and selectivity of the reaction are tabulated in Table 2 , along with the employed treatment.

\section{RESULTS AND DISCUSSION}

The results of the elemental analysis of untreated clays are presented in Table 3. In general, the used clays were of high silica and low alumina content. The kaolin content of alumina was higher than that of bentonite while iron was higher in bentonite. In comparing with kaolin clay from Algaof region (Albaroot et al., 2016), with lower silica and higher alumina, it is obvious that the composition of clay depends on the region that was collected from. It looks that samples that are taken from high altitudes and close to mountain sires will be enriched with alumina. However, iron contents of the samples are exceptionally high when compared with some other samples from different regions of the world (Shehu et al., 2017; Sabri and Sadeq, 1999; Sirait et al., 2017).

The BET surface area of bentonite and kaolin were of $200 \mathrm{~m}^{2} / \mathrm{g}$ and $15 \mathrm{~m}^{2} / \mathrm{g}$, respectively, and particle size analysis of both clays showed that $100 \%$ of particles were $<63 \mu \mathrm{m}$.

Alkylation reactions especially tert-butylation have been used for the protection of an active site in a specific compound during some chemical reactions. Green and solvent free catalysts with acid sites are needed for both alkylation and dealkylation reactions (Li, and Pidko, 2018). These acid sites could act as Lewis, Bronsted, or sometimes as both kinds of sites. The tert-Butyl group is often employed in the field of synthetic organic chemistry. In the presence of a Lewis acid, tert-butyl group undergoes detert-butylation; thus tert-butyl group is widely used as a positional protective group in the synthesis of phenolic compounds (Tashiro, 1979; Peter, 2007).

In the debutylation reactions of 2-tertbutylphenols using the catalysts of this work, the following products were detected; phenol, isobutene gas, 4-tertbutylphenol and small amounts of 2,4-di-tertbutylphenol. The latter product results from a disproportionation reaction. The same products were also reported by other researchers (Sabri and Sadeq, 1999). Twenty three clay samples varies from parent, calcined/or reduced, metal ions impregnated, and Ce ions exchanged were applied owing to enhance reactivity and selectivity of debutylation reactions of 2-tert-butylphenol at $210{ }^{\circ} \mathrm{C}$ (Table 2). Pure alumina and activated charcoal were also applied for comparison. Some elected results were presented in Figures 2-7. The percentage of conversion (\%conv.) after $30 \mathrm{~min}$ of reaction initiation and selectivity for different products at $80 \%$ conversion are given in Table 4 . The data for the reaction in which pure alumina or activated charcoal are seen as null since there was not any detectable conversion. This agrees with the fact that the removal of tert-butyl group from aromatic ring requires an excess of traditional acidic catalysts such as $\mathrm{AlCl}_{3}$ or $\mathrm{H}_{2} \mathrm{SO}_{4}$ (Anil et al., 2002).

Aluminum ions and $\mathrm{Si}^{4+} / \mathrm{Al}^{3+}$ ratios play an important role to control the number of acid sites on the catalyst surface (Lohse and Barbara, 1989). Therefoe, the high Aluminum content in clay, or the high $\mathrm{Si}^{4+} / \mathrm{Al}^{3+}$ ratio corresponds to the high number of Lewis acid sites. By looking at Table 3 we can see that kaolin has a high Aluminum and Silicon $\left(\mathrm{AI}^{3+}\right.$ and $\left.\mathrm{Si}^{4+}\right)$ content. This would result in a higher number of acid sites than bentonite and thereby more active catalyst in the debutylation reactions. Indeed, it is found that kaolin is the most active catalyst. For example, after 30 minutes of reaction, kaolin gave 90\% (Figure 2) conversion, while bentonite (Figure 3) gave only $36 \%$ conversation.

The calcined catalysts were found to be more active than those reduced with the same composition. All acid treated and calcined catalysts have gained more Brönsted and Lewis acid sites by this pretreatment. Therefore, these catalysts have shown a comparatively high debutylation activity versus other. Whereas, when these catalysts are reduced, some of their activity is lost due to the destruction of some of their Lewis acid sites. It is seen that the activity of these clays has increased upon impregnation with metals except for calcined Pt/bentonite, which showed low activity ( $<10 \%$ conversion). The reduced Pt/kaolin was less active than kaolin clay. Kaolin and bentonite clays impregnated with cerium showed strong catalytic activity enhancement. Introducing cerium into the clay results in increase its catalytic activity significantly, implying that the catalyst acidity was strongly enhanced. 
Table 3: Chemical analysis of major element in the Yemeni clays

\begin{tabular}{cccccc}
\hline Element & $\begin{array}{c}\text { Elemental } \\
\text { Composition of } \\
\text { Bentonite (ppm) }\end{array}$ & $\begin{array}{c}\text { Elemental composition } \\
\text { of Kaolin (ppm) }\end{array}$ & Component & $\begin{array}{c}\text { Bentonite } \\
\text { Composition } \\
\text { Weight (\%) }\end{array}$ & $\begin{array}{c}\text { Kaolin } \\
\text { Composition } \\
\text { Weight (\%) }\end{array}$ \\
\hline $\mathrm{Si}$ & 67.20 & 62.58 & $\mathrm{SiO}_{2}$ & 70.80 & 65.93 \\
$\mathrm{Al}$ & 13.97 & 24.75 & $\mathrm{Al}_{2} \mathrm{O}_{3}$ & 13.19 & 23.38 \\
$\mathrm{Fe}$ & 11.10 & 2.43 & $\mathrm{Fe}_{2} \mathrm{O}_{3}$ & 7.93 & 1.74 \\
$\mathrm{Ni}$ & 0.54 & 0.25 & $\mathrm{NiO}$ & 0.34 & 0.16 \\
$\mathrm{Mg}$ & 0.12 & 0.21 & $\mathrm{MgO}$ & 0.095 & 0.21 \\
$\mathrm{~K}$ & 2.94 & 1.60 & $\mathrm{TiO}_{2} \mathrm{O}$ & 2.07 & 1.13 \\
$\mathrm{Ti}$ & 1.49 & 2.14 & $\mathrm{CaO}$ & 0.24 & 1.79 \\
$\mathrm{Ca}$ & 0.35 & 0.63 & $\mathrm{Na}_{2} \mathrm{O}$ & 1.52 & 0.44 \\
$\mathrm{Na}$ & 1.79 & 5.38 & & & 4.6 \\
\hline
\end{tabular}

Table 4: A comparison of catalytic activity and selectivity of all catalysts used in the debutylation of 2-tertbutylphenol

\begin{tabular}{cccccc}
\hline Catalysts & Treatments & \multirow{2}{*}{ \% Conv. after 30 min. } & \multicolumn{3}{c}{ Selectivity at 80\% conv. } \\
\cline { 4 - 6 } Pure alumina & - & - & - & - & - \\
Activated charcoal & - & - & - & - & - \\
Ce-bentonite & Without treatment & 100 & 79 & 21 & - \\
Ce-kaolin & Without treatment & 100 & 50 & 50 & - \\
Ce-bentonite & Calcined & 74 & 46 & 35 & 19 \\
Ce-kaolin & Calcined & 99 & 60 & 40 & - \\
Ce-bentonite & Reduced & 9 & 35 & 62 & 3 \\
Ce-kaolin & Reduced & 99 & 65 & 35 & - \\
Bentonite & Calcined & 36 & 44 & 39 & 17 \\
Kaolin & Calcined & 91 & 65 & 21 & 14 \\
Bentonite & Reduced & 11 & - & - & - \\
Kaolin & Reduced & 100 & 55 & 43 & 2 \\
$5 \%$ Pt/bentonite & Reduced & 14 & 30 & 62 & 8 \\
$5 \%$ Pt/kaolin & Calcined & 99 & 46 & 54 & - \\
$5 \%$ Pt/kaolin & Reduced & 46 & 59 & 20 & 21 \\
$5 \%$ Pd/bentonite & Calcined & 48 & 50 & 36 & 14 \\
$5 \%$ Pd/bentonite & Reduced & 10 & - & - & - \\
$5 \%$ Pd/kaolin & Calcined & 87 & 56 & 29 & 15 \\
$5 \%$ Pd/kaolin & Reduced & 52 & 38 & 54 & 8 \\
$5 \%$ ( Pt- Ce )/bentonite & Reduced & 24 & 55 & 37 & 8 \\
$5 \%$ ( Pt- Ce)/kaolin & Calcined & 92 & 60 & 37 & 3 \\
$5 \%$ ( Pd- Ce )/bentonite & Calcined & 66 & 50 & 27 & 23 \\
$5 \%$ (Pd- Ce )/kaolin & Calcined & 64 & 41 & 48 & 11 \\
$5 \%$ ( Pd- Ce )/kaolin & Reduced & 6 & - & - & - \\
\hline
\end{tabular}

This was observed in this work in which the debutylation conversion approached $100 \%$ after $30 \mathrm{~min}$. Moreover, introduction of cerium might improve surface morphology which led to better selectivity for debutylation product
(50\%). One more important feature can be realized when we have a look at Figure 3, where we can observe that the curve of the debutylation product (\%phenol) declines after crossing the maximum. This indicates that the debutylation 
product (phenol) may undergo further reaction. The latter could be an alkylation to from the 4-tert-butylphenol, the isomer of the substrate, since the curve of \%4-TBPH (4tert-butylphenol) rises in parallel to the that decline. The benefits of cerium in the catalytic activity of parent clays have been already reported with kaolin (Junwei et al., 2018). Though cerium ion was introduced into the clays in the form of Ce(III), it is easily oxidized to Ce(IV) which is more stronger Lewis acid (Levin et al., 2015, Krause et al., 1992 ). Calcination or reduction of the Ce-Clay resulted in decrease of the reactivity and selectivity, which can be attributed to changing surface morphology due to calcination and conversion of Ce(IV) to less Lewis acidic $\mathrm{Ce}(\mathrm{III})$ due to reduction.

Surprisingly, Incorporation of the metal ions Pt into both clays individually or along with cerium resulted in diminishing the catalytic activity. This can be related to the effect on surface morphology properties, such as surface area, pore diameter and pore distribution. It was reported that, irrespective of clay used, $70-70 \%$ of platinum dispersions tend to immobilized in the interlammellar spaces, resulting in low reaction rate (Szollosi et al, 2001). Slight different behavior has been observed when changing the impregnating metal from Platinum to Palladium. The calcined Pd/bentonite showed almost 50\% conversion after 30 minutes. Therefore, the activity of Palladium impregnated clays is higher than those of Platinum impregnated ones.

An interesting result that can be debriefed from that data in Table 4 is that the selectivity of the catalysts changes depending on the kind of treatment of the catalyst. In general, the calcined catalysts have higher selectivity towards isomerization because of the high abundant of their acid sites. On the other hand, the reduced catalysts are the Bronsted/Lewis acid sites ratio would change leading to higher debutylation selectivity. However, the debutylation selectivity of the reduced $\mathrm{Pt} /$ bentonite has not changed when compared with the un-impregnated bentonite. Whereas, for the Pt/kaolin catalysts, the debutylation selectivity of the calcination treated catalysts was increased, and that of those treated by reduction was decreased compared to the unimpregnated clay.

\section{CONCLUSIONS}

From the obtained data, it was concluded that the tested calcined catalysts are more active than the reduced ones of the same composition. This can be attributed to the increase in the number of Lewis acid sites upon calcinations which resulted from the formation of metal oxides. So catalyst pretreatment plays an important role in deciding which catalyst to be used for a specific reaction. In comparison with the other catalysts, kaolin proved to be a better catalyst and catalyst support in this respect. It has been shown, after being calcined, reduced or ion-exchanged, that its activity is the highest but of lower debutylation selectivity. While bentonite exhibited lesser activity but debutylation selectivity was higher compared to kaolin. It is then worthwhile to state that Ce-bentonite, before being calcined or reduced, is the best catalyst for isomerization. It gives $100 \%$ conversion after 30 minutes with isomerization selectivity of $79 \%$ at $80 \%$ conversion.

\section{ACKNOWLEDGEMENTS}

Mohammed Hassan is grateful to IIE, New York for granting SRF fellowship.

\section{REFERENCES}

Albaroot, M., Ahmad, A. H. M., Al-Areeq, N., Sultan, M., 2016. Tectonostratigraphy of Yemen And Geological Evolution: A New Prospective, International Journal of New Technology and Research 2(2)19-33.

AL-Shameri, A., Lei, X.R., 2009. Characterization and Evaluation of Algaof Kaolin Deposits of Yemen for Industrial Application, American J. of Engineering and Applied Sciences 2(2), 292-296.

Anil, W., Jagannath, D., Muthukumaru P.S., Ravindranathan, M., 2002. Disproportionation, isomerization and de-tertbutylation of 2,6-di-tert-butylphenol catalyzed by $\mathrm{H}$ MCM-41, Green Chemistry 4, 587-591.

Cremades, L.V., Cusido J.A., Soriano, C., Devant, M., 2014. Using solid wastes as raw materials, In: Clay bricks, in: Wesley, L.R.(Ed.), clays and clay minerals geological origin, mechanical properties and industrial applications, Nova Science Publishers Inc., New York ,pp. 145-181.

Emam, A.E., 2013. Clays as catalysts in petroleum refining industry, ARPN Journal of Science and Technology 3(4), 356-375.

Junwei, L., Zhi, Y., Xia, G., 2018. Ce/Kaolin Clay As an Active Catalysts for Fatty Acid Methyl Esters Production From Cotton Seed Oil in A New Integrated Apparatus, Brazilian Journal of Chemical Engineering 35(1),147-154.

Kim, M. H., Choi, G., Elzatahry, A., Vinu, A., Choy, Y.B., Choy, jH., 2016. Review of clay-drug hybrid materials For biomedical applications: administration routes. Clays and Clay Minerals 64(2), 115-130.

Krause, K.R., Schabes-Retchkiman, Schmidt L.D., 1992. Microstructure of Rh-Ce Particles on Silica: Interactions Between Ce and $\mathrm{SiO}_{2}$, Journal of Catalysis 134, 204-219.

Levin, R.J., Dorfner, W.L., Carroll, P.J., Schelter E.J., 2015. Control of cerium oxidation state through metal complex secondary structures. Chemical Science 6, 6925-6934.

Li, G., Pidko, E.A. 2019. The nature and catalytic function of cation sites in zeolites: A computational perspective. ChemCatChem 11, 134-156.

Loganathan, N., Yazaydin, A.O., Bowers G.M., Kalinichev, A.G., Kirkpatrick R.J., 2016. Cation and water structure, dynamics, and energetics in smectite clays: A molecular dynamics study of Ca-hectorite. The Journal of Physical Chemistry C 120(23), 12429-12439. 
Lohse U., Barbara. P., 1989. Y zeolite acidity dependence on the S/AI ratio. The Journal of Physical Chemistry 93, 3677-3683.

Lussier, R.J., 1991. A novel clay based catalytic material: preparation and properties. Journal of Catalysis 129, 225-237.

Murray, H., 2007. Applied clay mineralogy occurrences, processing and application of kaolins, bentonites, palygorskite-sepiolite, and common clays ( $1^{\text {st }}$ edition). Elsevier, Amsterdam.

Novikova, L., Roessner, F., Al- Sawalha, M., Krupskaya, V., 2014. Study of surface acid-base properties of natural clays and zeolite by the conversion of 2-methylbut-3-yn2-ol. Applied Clay Science 101, 229-236.

Occelli, M.L., Drake, B., Gould S.A., 1993. Characterization of pillared montmorillonites with the atomic force microscope (AFM). Journal of Catalysis 142(2), 337-348.

Peter, G.M., Theodora, W.G., 2007. Greene's Protective Groups in Organic Synthesis (4th Edition), John Wiley and Sons. Pp. 87.

Sabri, M., Sadeq, A.S , 1999. Effect of acid activation on the detert-butylation activity of some Jordanian clays. Clay and Minerals 47(4), 481-486.

Savic, I., Stojiljkovic, S., Savic I. and Gajic, D., 2014. Industrial application of clays and clay minerals, in: Wesley, L. R.(Ed.), clays and clay minerals geological origin, mechanical properties and industrial applications, Nova Science Publishers Inc., New York, Pp. 379-402.

Shehu, Y., Salwah J.S., Azam, B.N., Dahiru, A.A., 2017. Chemical composition and particle size analysis of kaolin, Path of Science 3(10), 1001-1004.

Sirait, M., Bukit, N., Siregar, N., 2017. Preparation and characterization of natural bentonite in to nanoparticles by co-precipitation method, AIP Conference Proceedings. AIP Publishing LLC, Pp. 020006.

Szollosi, G., Kun, I., Mastalir, A., Bartok, M., Dekany Imre, 2001. Preparation, characterization and application of platinum catalysts immobilized on clays. Solid State Ionics 141-142, 273-278.

Tashiro M., 1979. Selective synthesis of aromatic compounds using positional protective groups, Synthesis (12), 921936.

Uddin, F., 2018. Montmorillonite: An introduction to properties and utilization, in: Zoveidavianpoor, M., Current topics in the utilization of clay in industrial and medical applications, IntechOpen, Pp. 3-23.

Varga, G., 2007. The structure of kaolinite and metakaolinite. Epitoanyag-Journal of Silicate Based and Composite Materials 59(1), 6-9.

Vicente, M.A., Trujillano, R., Ciuffi, K. J., Nassar E. J., Korili, S. A., Gil, A., 2010. Pillared Clay Catalysts in Green Oxidation Reactions, in: Gil, A., Korili, S.A., Trujillano, R., Vicente, M.A., Pillared Clays and Related Catalysts, Springer, New York, Pp. 301-318.
Visit us at: http://bosaljournals.com/chemint/ Submissions are accepted at: editorci@bosaljournals.com 